Revista Universo Contábil, ISSN 1809-3337

Blumenau, v. 15, n. 4, p. 49-68, out./dez., 2019

doi:10.4270/ruc.2019427

Disponível em www.furb.br/universocontabil

\title{
MUDANÇAS ESTRUTURAIS NO MERCADO DE TRABALHO ASSALARIADO CONTÁBIL BRASILEIRO
}

\section{STRUCTURAL CHANGES IN THE WAGE LABOR MARKET BRAZILIAN ACCOUNTING}

\section{CAMBIOS ESTRUCTURALES EN EL MERCADO DE TRABAJO ASALARIADO CONTABLE BRASILEÑO}

Recebido em: 04-05-2018

Avaliado em: 22-05-2020

Reformulado em: 30-11-2020

Aceito para publicação em: 01-12-2020

Publicado em: 31-12-2020

Editor Responsável: Marcia Zanievicz Silva

\author{
César Augusto Tibúrcio Silva ${ }^{1}$ \\ Paulo Vitor Souza de Souza ${ }^{2}$ \\ Polyana Batista da Silva ${ }^{3}$
}

\section{RESUMO}

O mercado de trabalho contábil no Brasil vem passando por diversas alterações, por vários motivos: diferenças de gênero, educação especializada, localização geográfica das empresas contábeis e outros. Entender as nuances do mercado de trabalho de uma profissão nos faz pensar sobre sua evolução histórica em determinado período, e projetar estratégias de ação como profissionais. Esta pesquisa verificou as mudanças estruturais ocorridas no mercado de trabalho formal do setor contábil brasileiro entre os anos de 2003 a 2018. Utilizamos a base de dados disponibilizada pelo Ministério do Trabalho e Emprego, especificamente as declarações submetidas na Relação Anual de Informações Sociais (RAIS), observando a concentração geográfica, escolaridade, gênero, remuneração, tipo de função e idade do trabalhador. Os resultados indicam que profissionais com nível superior estão sendo absorvidos, mais fortemente, pelo mercado; que houve aumento de contratação de profissionais do gênero feminino; que o nível de escolaridade influencia no valor do salário; que o salário de trabalhadores do gênero masculino é superior ao percebido pelas trabalhadoras do gênero feminino; que houve redução de cargos técnicos; e que a idade média dos trabalhadores diminuiu.

Palavras chave: Profissão Contábil; Mercado de Trabalho Contábil; RAIS.

\section{ABSTRACT}

The accounting labor market in Brazil has undergone several changes, for several reasons: gender differences, specialized education, geographic location of accounting firms, and others. Understanding the nuances of a job's job market makes us think about its historical evolution in a given period, and design action strategies as professionals. This research verified the structural changes that occurred in the formal labor market of the Brazilian accounting sector between the years

\footnotetext{
${ }^{1}$ Doutor em Controladoria e Contabilidade pela Universidade de São Paulo (USP); Professor Titular do Programa de PósGraduação em Ciências Contábeis da Universidade de Brasília; E-mail: cesartiburcio@unb.com

2 Doutorando em Ciências Contábeis na Universidade de Brasília (UnB); Professor Assistente da Faculdade de Ciências Contábeis da Universidade Federal Rural da Amazônia; E-mail: paulosouzx@ gmail.com

${ }^{3}$ Mestre em Ciências Contábeis pela Universidade do Estado do Rio de Janeiro (UERJ); Professora Substituta da Faculdade de Ciências Contábeis da Universidade Federal do Pará (UFPA); E-mail: polybsilva@gmail.com
} 
2003 to 2018. We use the database made available by the Ministry of Labor and Employment, specifically the statements submitted in the Annual List of Social Information (RAIS), observing the geographical concentration, education, gender, remuneration, type of function and age of the worker. The results indicate that professionals with higher education are being absorbed, more strongly, by the market; that there was an increase in the hiring of female professionals; that the level of education influences the value of the salary; that the salary of male workers is higher than that perceived by female workers; that there was a reduction in technical positions; and that the average age of workers has decreased.

Keywords: Accounting Profession; Accounting Labor Market; RAIS .

\section{RESUMEN}

El mercado laboral contable en Brasil ha experimentado varios cambios, por varias razones: diferencias de género, educación especializada, ubicación geográfica de las firmas contables, entre otras. Comprender los matices del mercado laboral de un trabajo nos hace pensar en su evolución histórica en un período determinado y diseñar estrategias de actuación como profesionales. Esta investigación verificó los cambios estructurales ocurridos en el mercado laboral formal del sector contable brasileño entre los años 2003 a 2018. Se utilizó la base de datos proporcionada por el Ministerio de Trabajo y Empleo, específicamente las declaraciones presentadas en el Relación Anual de Información Social (RAIS), observando la concentración geográfica, educación, género, remuneración, tipo de función y edad del trabajador. Los resultados indican que los profesionales con educación superior están siendo absorbidos, con mayor fuerza, por el mercado; que hubo un aumento en la contratación de mujeres profesionales; que el nivel de educación influye en el valor del salario; que el salario de los trabajadores varones es superior al percibido por las trabajadoras; que hubo una reducción de puestos técnicos; y que la edad media de los trabajadores ha disminuido.

Palabras-clave: Contabilidad de profesión; Contabilidad del mercado laboral; RAIS.

\section{INTRODUÇÃO}

As mudanças constantes observadas na economia mundial influenciam no processo produtivo e do trabalho em diversos países contribuindo para o aumento do desemprego em nível internacional (Araújo \& Antigo, 2016). Isso implica na maior flexibilização do uso do capital e do trabalho por parte das empresas, resultando na redução de custos, sobretudo nos custos da mão de obra (Gomes, 2002).

As empresas vêm se adaptando às novas configurações do mercado de trabalho, trazendo alterações na estrutura dinâmica das profissões, influenciando taxas de desemprego, precarização das condições de trabalho, diminuição do emprego nas indústrias, redução do trabalho assalariado, aumento do trabalho sem registro e temporário. $\mathrm{O}$ aumento significativo da participação do setor informal, do trabalho flexível e o aumento da exclusão social são reflexos dessas mudanças (Gomes, 2002).

Essa reconfiguração no mercado de trabalho tem implicações no presente e no futuro, resultando em novas condições de funcionamento desse mercado, com efeitos econômicos e sociais, produzindo uma elevação do perfil de qualificação da mão de obra, aprofundando a desigualdade na sociedade e na economia brasileira (Dedecca, 2002). Entende-se que há aumento da subcontratação, queda do padrão salarial, ampliação de contratos de trabalho temporários e aumento do desemprego, constituindo-se uma realidade que afeta todos os trabalhadores no mercado de trabalho brasileiro (Cavalcante, 2010).

O mercado de trabalho contábil é influenciado por fatores como alterações tecnológicas, órgãos reguladores e organizações (Pires, Ott \& Damacena, 2010), o que requer atualização constante do profissional sobre mudanças sociais, legais e mercadológicas. Esse mercado também absorve e 
retém profissionais qualificados com graduação e pós-graduação (strictu e latu sensu), e principalmente os que se mantêm atualizados, acompanhando as nuances mercadológicas e as necessidades tecnológicas.

O monitoramento de mudanças no mercado de trabalho auxilia no julgamento sobre o grau de desenvolvimento econômico de uma nação e no monitoramento das mudanças mercadológicas (Zhou, \& Yin, 2020), bem como influencia a forma de contratação das empresas, ocasionando alterações na taxa de emprego e desemprego, aumento e diminuição do trabalho temporário e informal, melhoria e precarização das condições de trabalho, entre outros (Gomes, 2002).

A literatura aponta algumas teorias que podeam auxiliar a análise de mudanças estruturais no mercado de trabalho. A Teoria do Capital Humano $(\mathrm{TCH})$ sugere que os indivíduos que adquirem mais conhecimentos e habilidades para aumentar o valor do seu capital humano, aumentariam também a sua empregabilidade, produtividade, rendimento e salário. A Teoria da Segmentação de Mercado (TSM) sugere que o local onde o salário de um indivíduo é gerado influencia no montante recebido por ele (Martins, \& Monte, 2010). Por sua vez, a Teoria da Discriminação Salarial (TDS) explica o fenômeno de discriminação no mercado, quando indivíduos com mesma escolaridade e capacidade produtiva recebem remunerações diferentes em razão do gênero e da raça (Santana Júnior, \& Calado, 2017).

A literatura sobre o mercado de trabalho contábil no Brasil analisa o reflexo da formação e as variações salariais em regiões isoladas (Martins, \& Monte, 2010; Pires, Ott, \& Damacena, 2010; Martins et al., 2009; Andrade, Gonçalves, \& Freguglia, 2014; Araújo, \& Antigo, 2016; Silva et al., 2018), deixando de interpretar a análise global do país, excluindo algumas características ou utilizando um banco de dados limitado sem realizar análises aprofundadas.

O objetivo deste estudo é verificar as mudanças estruturais ocorridas no mercado de trabalho formal do setor contábil brasileiro. A pesquisa analisou aspectos relacionados à concentração geográfica, escolaridade, gênero, remuneração do setor, função e idade dos trabalhadores. Para isto foram coletados dados disponibilizados pelo Ministério do Trabalho e Emprego (MTE), referente às declarações prestadas anualmente pelos empregadores brasileiros por meio da Relação Anual de Informações Sociais (RAIS), no período de 16 anos, entre 2003 a 2018.

O lapso temporal do estudo - 16 anos - revela uma quantidade maior de mudanças no mercado de trabalho brasileiro, permitindo aos autores analisar um número maior de variáveis e correlações. Pretende-se, com este estudo, ampliar o conhecimento sobre as mudanças estruturais ocorridas no mercado de trabalho contábil brasileiro, por meio de uma análise temporal ampla desses fatores, além de contribuir com a literatura sobre o mercado de trabalho contábil, fornecendo evidências sobre os aspectos que geram diferenças salariais entre os profissionais. Também foram realizadas análises comparativas com a economia como um todo, incluindo todos os setores constantes da base de dados utilizada. Os resultados obtidos contribuíram para a discussão acadêmica e profissional sobre a necessidade de reduzir desigualdades nos salários destes profissionais.

Torna-se importante analisar o mercado de trabalho contábil por essa profissão ocupar um nicho distinto dentre as opções disponíveis, pois ao ingressar no mercado de trabalho o indivíduo possui certa segurança em empregabilidade e estabilidade (Leiby, \& Madsen, 2017). Conforme estudo da Bureau of Labor Statistics (BLS) (2016), há uma previsão de que a demanda de serviços de profissionais contábeis irá crescer em $10 \%$ entre 2016 e 2026, com o aumento substancial de vagas no mercado de trabalho mundial. Assim, dadas estas características, Martins et al. (2009) comentam que o mercado de trabalho contábil é promissor, cabendo estudos e análises dos fenômenos ocorridos nesse ambiente.

O conhecimento da desigualdade de gênero existente no mercado de trabalho contábil pode contribuir na gestão dos recursos humanos dos empregadores e para a implementação de políticas que visam minimizar essa desigualdade. Saliente que estamos considerando como gênero a distinção entre masculino e feminino, em decorrência da base de dados utilizada. 


\section{TEORIAS ECONÔMICAS SOBRE A VARIAÇÃO SALARIAL}

Algumas teorias econômicas podem explicar as condições que determinam a variação dos salários dos trabalhadores. Para Santana Júnior e Callado (2017, p. 71) "a microeconomia baseada na homogeneidade da mão de obra associa a determinação dos salários com o preço de qualquer outro bem, ou seja, atribui que a relação entre a oferta e a demanda de trabalho são determinantes dos salários".

As lacunas salariais existentes no mercado de trabalho têm origem, muitas vezes, na discriminação contra trabalhadores minoritários, que mesmo apresentando mesma capacidade e treinamento, recebem salários mais baixos por parte dos empregadores (Carneiro, Heckman, \& Masterov, 2005). Assim, a remuneração de uma determinada classe ou categoria de trabalhadores pode apresentar disparidade, o que também pode ser observado na classe dos profissionais de contabilidade. As principais razões dessas diferenças salariais entre os trabalhadores da contabilidade podem ser analisadas com teorias econômicas que abordam principalmente o investimento em capital humano e o meio em que o profissional está inserido (Martins et al., 2009).

O nível de escolaridade ou qualificação do profissional pode variar em uma mesma região e ser fator de diferenciação no mercado de trabalho e na empregabilidade dos profissionais de uma determinada área de conhecimento (Martins et al., 2009). Três correntes que explicam quais são os fatores que influenciam e determinam a empregabilidade do trabalhador são: a Teoria do Capital Humano (TCH), que se relaciona com o investimento em capital intelectual; a Teoria da Segmentação de Mercado (TSM), que se relaciona com o meio que o empregado está inserido; e, por fim, a Teoria da Discriminação Salarial (TDS) que se relaciona com as desigualdades de raça e gênero.

\subsection{Teoria do Capital Humano (TCH)}

A teoria do capital humano parte da observação de que na medida em que o nível educacional de um indivíduo cresce em relação a outro indivíduo ou grupo de pessoas, cresce também sua renda. Tem como princípio que quanto mais conhecimentos e habilidades são adquiridos pelo trabalhador, maior o valor do seu capital humano, o que aumentaria a sua empregabilidade, produtividade e rendimento potencial (Martins, \& Monte, 2010). O entendimento é de que os gastos em educação resultam em melhores retornos futuros para o ser humano (Blaug, 1976).

Pode-se considerar que a literatura sobre os motivos que explicariam a diferença salarial entre trabalhadores com diferentes níveis de escolaridade tem como precursores Mincer (1958) e Becker (1964), que apontam, dentre outros motivos, escolhas, habilidades e saúde individuais.

O capital humano explica o crescimento econômico das nações e a distribuição de renda entre os indivíduos (Martins et al., 2009). À medida que os investimentos para melhorar a capacidade aumentam, o valor do esforço humano - o trabalho - acompanha esse crescimento, resultando em uma taxa de retorno positiva para o trabalhador (Schultz, 1961).

Ao optarem pelo ensino superior, indivíduos estariam cientes que precisariam renunciar ganhos presentes. Portanto, as diferenças salariais estão relacionadas ao tempo de escolaridade que os indivíduos possuem, pois irão perceber que ao entrar no mercado de trabalho vários anos depois, o salário será substancialmente diferente do que se eles tivessem optado por não continuar os estudos (Blaug, 1976). Estudos sobre a influência do nível de escolaridade nos salários de contadores no Brasil têm como pano de fundo estados ou municípios brasileiros (Martins et al., 2009; Martins, \& Monte, 2010; Alves, 2015).

Por sua vez, a literatura internacional aponta que o desenvolvimento de recursos humanos dos profissionais contábeis de acordo com as exigências do mercado de trabalho contábil possui relação positiva com a qualidade dos serviços que são prestados por esses profissionais (Ha et al., 2020). A profissão contábil exige que seus profissionais invistam de forma significativa em capital humano, por meio de diplomas universitários, certificações e educação continuada (Leiby, \& Madsen, 2017). 


\subsection{Teoria da Segmentação de Mercado (TSM)}

Além do nível de educação, experiência e treinamento, há uma forte influência do local de onde o salário dos trabalhadores é gerado, o mercado de trabalho onde este trabalhador está inserido (Martins, \& Monte, 2010). Dessa forma, entende-se que os índices de contratação estariam relacionados ao nível de educação, qualificação profissional e às suas características gerais, adquiridas no segmento populacional em que esses trabalhadores estão inseridos (Souza, 1978). A TCH é relevante, por causa das características pessoais do trabalhador, mas essas características devem ser ponderadas pelo segmento e ambiente onde esse trabalhador está empregado.

É preciso atentar

[...] para a existência de diferentes tipos de mercado de trabalho, que é resultado de fatores econômicos, em que os níveis de formação educacional dos indivíduos ou das economias das regiões podem divergir, contemplando a formação voltada para atender o mercado onde o indivíduo está inserido (Martins, et al., 2009, p. 74).

A segmentação do mercado de trabalho acontece "quando os indivíduos possuem características semelhantes, mas os salários diferem entre eles" (Martins, \& Monte, 2010, p. 16). De acordo com a TSM, os salários têm mais a ver com os tipos de empregos que os trabalhadores têm acesso, com a forma de organização de trabalho e com a mobilidade ocupacional, do que com as características do trabalhador, como o seu nível de escolaridade alcançada (Lima, 1980). A eliminação de barreiras da mobilidade ocupacional entre os segmentos de mercado requer uma mudança na organização do trabalho das empresas (Lima, 1980).

A TSM foi constituída a partir do entendimento de que "[...] o mercado de trabalho pode apresentar barreiras à mobilidade, e estas barreiras são reflexos não apenas de diferentes níveis de conhecimento e habilidades, por parte da mão de obra, mas das próprias características do local onde o indivíduo desenvolve suas atividades profissionais" (Martins, \& Monte, 2010, p. 16). Por esses motivos, as diferenças salariais dependem tanto do nível de educação que o indivíduo possuí, quanto do ambiente onde esse indivíduo está inserido, podendo ser alteradas também pela localização geográfica.

Além das influências educacionais e geográficas, o gênero pode também ser um fator de alteração salarial, conforme Gomes e Souza (2018), ao apontarem que os homens estão em melhor situação do que as mulheres, pois possuem salários superiores, denotando assim a existência de discriminação de rendimentos contra as mulheres.

\subsection{Teoria da Discriminação Salarial (TDS)}

As teorias anteriores analisam as características de qualificação do trabalhador (TCH) e o mercado de trabalho onde esse indivíduo está inserido (TSM) com o salário recebido.Mesmo que indivíduos possuam características de capital humano e capacidade produtiva idênticas, podem ser remunerados de formas diferentes, de acordo com o gênero masculino ou feminino. A Teoria da Discriminação Salarial (TDS) procura explicar as diferenças salariais abordando desigualdades de raça e gênero (Santana Júnior, \& Callado, 2016). Nesta pesquisa, será levantada a discriminação salarial por gênero, em razão da base de dados utilizada que distingue as remunerações para os gêneros masculino e feminino.

A desigualdade de gênero é um problema agudo e persistente, principalmente quando se trata de países em desenvolvimento (Silva et al., 2018). A inclusão de mulheres no mercado de trabalho denota avanços e atrasos, pois mesmo com o aumento da participação feminina no mercado de trabalho, as más condições e o aumento da participação em atividades precárias e informais fazem com que ainda exista discriminação de gênero no mercado de trabalho (Silva et al., 2018).

A literatura sobre discriminação salarial entre gêneros analisa a relação entre discriminação e exclusão completa das mulheres no mercado de trabalho ou a exclusão de mulheres dos cargos 
gerenciais (Esteve-Volart, 2004); a diferença de gênero em treinamento, capital e salários, observando que mulheres são empregadas em cargos com menor duração de treinamento (Barron, Black, \& Loewenstein, 1993). Os tipos de desigualdade e discriminação entre gêneros no mercado de trabalho são constituídos principalmente pela inserção das mulheres em relação às oportunidades e remuneração desse mercado (Mattei, \& Baço, 2017).

O quantitativo menor de trabalhadoras do gênero feminino em níveis importantes no mercado de trabalho pode estar relacionado com a discriminação de gênero nessa relação de trabalho e trabalhadoras. Geralmente trabalhadoras do gênero feminino tendem a ser posicionadas em empregos em que os pagamentos são menores em relação ao de trabalhadores do gênero masculino em uma mesma posição (Mihaila, 2016).

De forma conceitual, essa discriminação é medida pela diferença salarial do gênero, como resultado quantificado que diz respeito aos membros individuais de um grupo minoritário (mulheres) em relação a um grupo majoritário - homens -, se manifestando por meio de menor remuneração do grupo feminino para o masculino (Vandenbergh, 2011; Gomes, \& Souza, 2018).

\subsection{Mercado de Trabalho Contábil - Estudos Anteriores}

A profissão contábil ocupa um nicho distinto dentre as opções de carreira disponíveis para os ingressantes do mercado de trabalho, pois essa profissão denota uma certa segurança em empregabilidade e estabilidade (Leiby, \& Madsen, 2017). Para Williamson (2019), a profissão contábil tem sido vista como uma profissão estável e que proporciona vida confortável aos seus membros.

O mercado de trabalho contábil é amplo e promissor (Martins et al., 2009). Essa afirmação é de 2009 e agora temos condições de comprovar se é razoável ou não. Além disto, essa assertiva foi realizada em condições ambientais diferentes da atual, o que cabe um certo cuidado em considerá-la válida para os dias de hoje. Uma análise histórica de como foi instaurada a profissão contábil no mercado brasileiro é importante

A profissão contábil exige altos investimentos em capital humano por meio de qualificações e educação continuada. O mercado de trabalho contábil tende a apresentar baixo desemprego, demanda estável e baixa variação salarial (Leiby, \& Madsen, 2017).

A previsão de crescimento na demanda de serviços de contadores e auditores deverá crescer $10 \%$ entre 2016 a 2026, adicionando 750 mil novas vagas no mercado (Bureau of Labor Statistics, 2016). Esse crescimento é justificado pela globalização, uma economia em crescimento e um ambiente fiscal e regulatório complexo, levando ao aumento da demanda de contadores e auditores. Além disso, o aumento do uso de dados e pesquisa de mercado para entender clientes e demanda de produtos e para avaliar estratégias de marketing levará à crescente busca e interesse por analistas de pesquisa de mercado (BLS, 2016).

Porém alguns cargos da profissão contábil têm apresentado desigualdade salarial entre seus membros, tornando assim, necessário incorporar sistemas que garantam a igualdade entre esses profissionais (Kyriakidou et al., 2016). A compreensão da existência de disparidade salarial no mercado de trabalho contábil afeta a produção de informações contábeis para empregadores, formuladores de políticas e reguladores, o que pode comprometer seus julgamentos sobre a contratação desses profissionais (Williamson, 2019).

\section{ASPECTOS METODOLÓGICOS DA PESQUISA}

Os dados desta pesquisa foram obtidos por meio da declaração prestada anualmente pelos empregadores do Brasil para o Ministério do Trabalho e Emprego (MTE). A Relação Anual de Informações Sociais (RAIS), instituída mediante Decreto $\mathrm{n}^{\circ} 76.900$ de 23 de dezembro de 1975, que tem como objetivo controlar a atividade trabalhista no Brasil; prover dados para elaboração de estatísticas no trabalho; e disponibilizar informações do mercado de trabalho às entidades 
governamentais (Brasil, 1975). Sendo assim, os dados utilizados por esta pesquisa são referentes ao mercado de trabalho formal ou de carteira assinada no Brasil. Eventuais remunerações não declaradas ou vínculo empregatício sem registro na carteira de trabalho não são captadas pela RAIS.

O horizonte temporal considerado nesta pesquisa compreende o período entre 2003 a 2018, sendo 2018 o último ano com dados disponíveis, no momento em que a pesquisa foi realizada. Existem dados anteriores a 2003, mas há problemas de comparabilidade, por motivo de mudança na Classificação Brasileira de Ocupações (CBO), e, por essa razão, a pesquisa limitou-se a esse horizonte temporal. Em muitos casos, foram apresentados resultados referentes ao último ano da pesquisa. Ao final de 2018 existiam cerca de 475.030 trabalhadores registrados no setor contábil, sendo esses indivíduos considerados, assim, como a amostra do estudo.

Para determinar o setor contábil, optou-se por usar algumas famílias da CBO, que foi instituída pela Portaria Ministerial no 357 de 9 de outubro de 2002. Essa portaria "[...] tem por finalidade a identificação das ocupações no mercado de trabalho, para fins classificatórios junto aos registros administrativos e domiciliares" (Brasil, 2002). O Quadro 1 apresenta as famílias selecionadas de acordo com a CBO:

Quadro 1 - Descrição das Famílias selecionadas de acordo com a CBO

\begin{tabular}{|c|c|}
\hline Código da CBO & Descrição da Família \\
\hline 2522 & Contadores e Auditores \\
\hline 4131 & Escriturários de Contabilidade \\
\hline 3511 & Técnicos em Contabilidade \\
\hline
\end{tabular}

Fonte: Elaborado pelos autores.

Neste estudo, os dados em unidades monetárias são considerados em salários mínimos. Acredita-se que, em virtude disso, não se faz necessário um tratamento dos valores para a inflação do período, tendo em vista que se utilizaram valores temporais comparativos. Em muitos anos o valor do salário mínimo excedeu a inflação oficial e em outros ficou abaixo da inflação, mas isso também não foi levado em consideração na análise, já que a discussão salarial, em muitas situações, está atrelada ao valor desse salário mínimo.

Em alguns casos, os valores obtidos na base de dados foram transformados usando as propriedades de subtração do valor esperado (E) e da variância (VAR), conforme denotam as Equações 1 e 2 dispostas a seguir:

$$
\begin{array}{cr}
E(X-Y)=E(X)-E(Y) & \text { Equação 1 } \\
\operatorname{VAR}(X-Y)=\operatorname{VAR}(X)+\operatorname{VAR}(Y) & \text { Equação 2 }
\end{array}
$$

Onde:

$E-$ Valor Esperado;

$V A R$ - Variância;

$X$ e $Y$ - Nos casos usados as variáveis X e Y são independentes entre si.

Neste estudo, que tem o intuito de verificar variáveis que estão relacionadas com a mudança estrutural no trabalho assalariado contábil brasileiro, torna-se relevante identificar quais as variáveis utilizadas nesta pesquisa. Em alguns momentos foram feitas análises descritivas dos dados por ano ou por categorias, e em outros momentos, análises de regressão linear simples para verificar a relação entre as variáveis dependentes e independentes. São identificadas no Quadro 2 as variáveis dependentes e independentes do estudo. 


\begin{tabular}{|c|c|c|}
\hline Variáveis Dependentes & Definição & Autores \\
\hline $\begin{array}{l}\text { Ensino Superior Completo } \\
\text { (ESC) }\end{array}$ & $\begin{array}{l}\text { Número de trabalhadores com curso superior no setor } \\
\text { contábil no período em análise. }\end{array}$ & $\begin{array}{l}\text { Araújo e Antigo (2015); Martins } \\
\text { et al. (2009); Martins e Monte } \\
\text { (2010); }\end{array}$ \\
\hline $\begin{array}{l}\text { Percentual do Curso } \\
\text { Superior (PCS) }\end{array}$ & $\begin{array}{l}\text { Percentual de trabalhadores que possuem curso } \\
\text { superior no setor contábil no período em análise. }\end{array}$ & Elaboração Própria. \\
\hline Gênero Feminino (GF) & $\begin{array}{l}\text { Número de mulheres que trabalham no setor contábil } \\
\text { no período em análise. }\end{array}$ & $\begin{array}{l}\text { Brighenti, Jacomossi e Silva } \\
\text { (2015); Martins et al. (2009); } \\
\text { Martins e Monte (2010); Silva, } \\
\text { Dal Magro e Silva (2016). }\end{array}$ \\
\hline $\begin{array}{l}\text { Percentual do Gênero } \\
\text { Feminino (PGF) }\end{array}$ & $\begin{array}{l}\text { Percentual de mulheres que trabalham no setor } \\
\text { contábil no período em análise. }\end{array}$ & Elaboração Própria. \\
\hline $\begin{array}{l}\text { Remuneração Média do } \\
\text { Setor (RMS) }\end{array}$ & $\begin{array}{l}\text { Remuneração média do setor (em salário mínimo) no } \\
\text { período de tempo em análise. }\end{array}$ & $\begin{array}{l}\text { Brighenti, Jacomossi e Silva } \\
\text { (2015); Martins e Monte (2010); } \\
\text { Martins et al. (2009); Silva, Dal } \\
\text { Magro e Silva (2016). }\end{array}$ \\
\hline $\begin{array}{l}\text { Diferença da } \\
\text { Remuneração Média } \\
\text { (DRM) }\end{array}$ & $\begin{array}{l}\text { Diferença entre a remuneração do setor contábil e a } \\
\text { remuneração de todos os setores da economia no } \\
\text { período de tempo em análise. }\end{array}$ & Elaboração Própria. \\
\hline $\begin{array}{l}\text { Diferença da } \\
\text { Remuneração (DR) }\end{array}$ & $\begin{array}{l}\text { Diferença entre a remuneração do trabalhador com } \\
\text { que possui curso superior com a remuneração do } \\
\text { trabalhador que possui apenas ensino médio. }\end{array}$ & Elaboração Própria. \\
\hline $\begin{array}{l}\text { Idade Média do } \\
\text { Trabalhador (ID) }\end{array}$ & $\begin{array}{l}\text { Idade média do trabalhador no período de tempo em } \\
\text { análise. }\end{array}$ & $\begin{array}{l}\text { Araújo e Antigo (2015); } \\
\text { Brighenti, Jacomossi e Silva } \\
\text { (2015); Silva, Dal Magro e Silva } \\
\text { (2016). }\end{array}$ \\
\hline Variável Independente & Definição & \\
\hline Ano (ANO) & Período analisado (ano da ocorrência). & Elaboração Própria. \\
\hline
\end{tabular}

Fonte: Elaborado pelos autores.

O Quadro 2 evidencia nove variáveis, sendo oito dependentes e uma independente que serão testadas nos modelos de regressão linear simples. De forma geral, o modelo de regressão simples é apresentado conforme a Equação 3 a seguir:

$$
C S / P C S / G F / P G F / R M S / D R M / D R / I D=\beta 0+\beta 1 A N O+\mu
$$

Equação 3

Percebe-se na Equação 3 que as variáveis CS, PCS, RMS, DMR, DR e ID, que estão antes da igualdade, são consideradas variáveis dependentes do estudo que serão testadas em cinco modelos diferentes. A variável "ANO” é a única variável independente do estudo. O $\mu$ é o termo de erro do modelo.

Segundo Fávero (2015) são quatro os pressupostos do modelo de regressão. Em primeiro lugar, os resíduos apresentam distribuição normal; nos cálculos realizados, esse problema foi minimizado com a utilização de grandes amostras. O segundo aspecto é a multicolinearidade, em que as correlações entre as variáveis explicativas são elevadas e existem mais observações que variáveis explicativas, o que não é o caso, já que foi utilizado a regressão simples. A heterocedasticidade corresponde ao terceiro pressuposto, em que uma possível causa seria a omissão de uma variável relevante. Esse problema efetivamente pode ocorrer. Porém, em razão da forma como os dados foram coletados não é possível tratar esse aspecto de maneira adequada, sendo uma limitação deste trabalho. Finalmente, pode existir autocorrelação dos resíduos, sendo que esses resíduos não são aleatórios e independentes.

As principais causas desse problema, em séries temporais, são os aspectos sazonais e podem ser tratados, por exemplo, pela inclusão de uma variável omitida. Acredita-se que possa existir autocorrelação dos resíduos em razão da recessão ocorrida nos últimos anos da série, mas optou-se 
pelo modelo linear simples e a informação obtida pelo coeficiente angular. Ademais, a regressão não foi usada para fazer projeções, o que reduz o impacto desses problemas.

Além de análises inferenciais, foram proferidas algumas análises referentes ao Coeficiente Gini. O Coeficiente de Gini é representado por um número contínuo entre o intervalo 0 e 1 , onde 0 corresponde à maior igualdade e 1 à maior desigualdade salarial em uma determinada sociedade. Conforme Barros, Henriques e Mendonça (2000), esse coeficiente compreende um indicador consagrado e de uso difundido na literatura que revela o grau de desigualdade de renda de uma realidade específica, no caso desse estudo, o Brasil.

Foram realizadas, ainda, análises descritivas para as características relacionadas à escolaridade, gênero, tipo de função e idade. Sendo assim, a próxima seção demonstra os resultados da pesquisa por meio de análises inferenciais, de coeficiente de Gini e análises descritivas.

\section{ANÁLISE DOS DADOS}

Esta seção visa fornecer os resultados da pesquisa mediante tabelas e figuras que evidenciam as análises descritivas e inferenciais sobre: concentração geográfica, mudanças estruturais, remuneração, educação, gênero, função e idade do trabalhador do setor contábil.

\subsection{Análise Descritiva por Concentração Geográfica}

No final do ano de 2018 existiam 475.030 trabalhadores registrados no setor contábil. Por volta de $62 \%$ desses empregados eram mulheres e o estado de São Paulo detinha um terço desse total, seguido por Minas Gerais (10\%) e Rio de Janeiro (8\%). Assim, esses três estados do Sudeste tinham mais da metade dos trabalhadores do setor; um índice um pouco menor que existia em 2003, quando a participação dos três estados na força de trabalho era de 55\%. O resultado corrobora com Andrade, Gonçalves e Freguglia (2014), que apontaram, também, esses três estados com maior concentração de trabalhadores na economia como um todo, independente de setor. Assim, nota-se que o setor contábil acompanha a concentração geográfica da economia. Neste intervalo de tempo (2003 - 2018), ocorreu um crescimento de $4,9 \%$ ao ano, de trabalhadores na área contábil brasileira; valor acima do crescimento da população.

Entretanto, essa concentração geográfica espelha principalmente a concentração econômica. Para inferir isso, já que foi calculado o coeficiente de Gini para distribuição da folha salarial entre as unidades da federação e o resultado foi de 0,65 para 2018 - era 0,71 em 2003. Esse resultado indica uma concentração geográfica, já que quanto mais próximo da unidade, mais concentrada é a distribuição da renda. Além disso, a correlação entre os valores da folha de pagamento por unidade da federação em relação ao PIB per capita e o Produto Interno Bruto (PIB) de cada unidade apresentou uma correlação bastante elevada: 0,99 para PIB e 0,44 para PIB per capita. Ainda sobre a concentração geográfica é importante destacar que somente a cidade de São Paulo concentrava $14,5 \%$ da força de trabalho da área, seguida da cidade do Rio de Janeiro, com 5,0\%, totalizando $19,5 \%$.

Portanto, nota-se que no mercado de trabalho contábil brasileiro há uma possível influência do local onde esse profissional está inserido, pois conforme os dados da pesquisa, há uma concentração geográfica dos profissionais na região Sudeste. Esse resultado corrobora com o estudo de Andrade, Gonçalves e Freguglia (2014), que evidenciam que os trabalhadores estão distribuídos de forma desigual pelas regiões metropolitanas no Brasil, com maior participação nas capitais de São Paulo, Rio de Janeiro e Minas Gerais.

Não foi proferida uma análise das diferenças salariais entre as regiões, porém, a concentração desses profissionais no Sudeste do país nos fornecem algumas evidências associadas com a Teoria da Segmentação de Mercado (TSM), a qual aponta que o local onde o profissional está inserido tende a influenciar em seu salário (Martins, \& Monte, 2010). Portanto, conforme a concentração de 
profissionais nesses estados, nota-se uma possível movimentação de profissionais de todas as outras regiões do Brasil para esses estados pela possibilidade de salários maiores.

\subsection{Análise das Mudanças Estruturais no Mercado de Trabalho Contábil Brasileiro}

Torna-se importante evidenciar os resultados relacionados às principais mudanças estruturais observadas no mercado de trabalho contábil brasileiro, relacionadas à escolaridade, em sua distribuição e evolução, e quantitativo de força de trabalho feminina.

A Tabela 1 apresenta a distribuição dos trabalhadores pelo grau de escolaridade. Para fins comparativos, apresenta-se também a distribuição de escolaridade dos trabalhadores, quando se considera toda a economia. É nítida a melhor qualificação existente entre os empregados do setor contábil: quase a metade possui o curso superior completo, enquanto que na economia essa qualificação está presente em um quinto dos trabalhadores. Além disso, a Tabela 1 apresenta a situação em 2003. No passado $60 \%$ da força de trabalho do setor contábil não tinha o curso superior, versus $48 \%$ no final de 2018. O número de trabalhadores desse setor com o título de mestre cresceu de 457 (dado de 2006) para 4.082; o mesmo ocorreu com o número de trabalhadores com do título de doutorado, de 80, em 2006, para 376.

Tabela 1 - Distribuição dos trabalhadores pela Escolaridade - 31/12/2018

\begin{tabular}{lccc}
\hline Escolaridade & Setor Contábil 2018 & Economia & Setor Contábil 2003 \\
\hline Ensino Fundamental Completo & $1,57 \%$ & $18,05 \%$ & $6,96 \%$ \\
Ensino Médio Incompleto & $1,62 \%$ & $6,12 \%$ & $4,82 \%$ \\
Ensino Médio Completo & $30,29 \%$ & $48,85 \%$ & $36,92 \%$ \\
Ensino Superior Incompleto & $14,99 \%$ & $3,97 \%$ & $11,61 \%$ \\
Ensino Superior Completo & $51,53 \%$ & $23,01 \%$ & $39,69 \%$ \\
\hline Total (\%) & $\mathbf{1 0 0 , 0 0 \%}$ & $\mathbf{1 0 0 , 0 0 \%}$ & $\mathbf{1 0 0 , 0 0 \%}$ \\
\hline Número de trabalhadores & $\mathbf{4 7 5 . 0 3 0}$ & $\mathbf{4 6 . 6 3 1 . 1 1 5}$ & $\mathbf{2 2 1 . 0 7 5}$ \\
\hline
\end{tabular}

Fonte: Resultados da Pesquisa.

Para verificar o crescimento da escolaridade dos trabalhadores foi calculada uma regressão linear simples, tendo o período de tempo como variável independente. Em uma primeira expressão, usou-se o número de trabalhadores com Ensino Superior Completo (ESC) no setor contábil e o resultado vem demonstrado na Tabela 2.

Tabela 2 - Evolução da Escolaridade do Profissional Contábil - Valores Absolutos

\begin{tabular}{lcc}
\hline & Coeficiente & Significância \\
\hline Constante & 62150,0 & $* * *$ \\
$\mathrm{ANO}$ & 10955,2 & $* * *$ \\
\hline $\mathrm{R}^{2}=0,99 ; \mathrm{F}(1,14)=1083,53$ & & \\
\hline Equação: $\mathrm{CS}=62150,0+10955,2$ x ANO & & \\
\hline
\end{tabular}

Legenda: *** corresponde à significância estatística no nível de $1 \%$.

Fonte: Resultados da Pesquisa.

A Tabela 2 apresenta o resultado da regressão simples ESC e ANO. O sinal positivo indica que a cada ano há mais trabalhadores com formação superior. Entretanto, a equação anterior pode não expressar uma qualificação do setor, já que o número de trabalhadores pode estar crescendo de maneira vegetativa. Para confirmar isso, foi calculada outra regressão simples, usando agora o percentual dos trabalhadores com ensino superior. O resultado está representado na Tabela 3. 
Tabela 3 -Evolução da escolaridade do profissional contábil - valores percentuais

\begin{tabular}{lcc}
\hline & Coeficiente & Significância \\
\hline Constante & 0,3511 & $* * *$ \\
ANO & 0,0080 & $* * *$ \\
\hline
\end{tabular}

$\mathrm{R}^{2}=0,83 ; \mathrm{F}(1,14)=67,905$

Equação: PSC $=0,3511+0,0080 \times$ ANO

Fonte: Resultados da Pesquisa.

Legenda: *** corresponde à significância estatística no nível de $1 \%$.

O resultado apresentado na Tabela 3 evidencia que a cada ano há um aumento de $0,8 \%$ na participação dos trabalhadores com o ensino superior completo. Mantido esse percentual e partindo de $51 \%$, seria possível estimar que, em 70 anos, toda força de trabalho teria esse nível de escolaridade. Essa análise permite inferir a existência de uma mudança estrutural no mercado de trabalho do setor contábil nos últimos anos.

Existe outra mudança relevante que ocorreu nesse período referente à composição da força de trabalho segundo o gênero. No final de 2018, 62\% dos trabalhadores eram do gênero feminino, enquanto que na economia como um todo esse percentual correspondia a $44 \%$ no mesmo período. A relação entre o número de mulheres e o período de tempo são calculadas mediante regressão linear simples conforme evidencia a Tabelas 4.

Tabela 4 - Evolução do número de mulheres no setor contábil

\begin{tabular}{lcc}
\hline & Coeficiente & Significância \\
\hline Constante & 8894,5 & $* * *$ \\
ANO & 13748,7 & $* * *$ \\
\hline $\mathrm{R}^{2}=0,97 ; \mathrm{F}(1,14)=452,70$ & & \\
\hline Equação: $\mathrm{PSC}=8894,5+13748,7$ x ANO & & \\
\hline
\end{tabular}

Fonte: Resultados da Pesquisa.

Legenda: *** corresponde à significância estatística no nível de $1 \%$.

O resultado referente ao gênero, pelo ano, indicou um acréscimo anual de 13,5 mil trabalhadoras por ano. Ou seja, as mulheres têm adentrado no mercado de trabalho contábil de forma substancial ao longo dos últimos anos, mediante os resultados que foram evidenciados na Tabela 4. Por sua vez, a análise percentual do quantitativo de mulheres pelo período de tempo é evidenciada na Tabela 5.

Tabela 5 - Evolução da participação das mulheres na força de trabalho

\begin{tabular}{lcc}
\hline & Coeficiente & Significância \\
\hline Constante & 0,4777 & $* * *$ \\
$\mathrm{ANO}$ & 0,0093 & $* * *$ \\
\hline $\mathrm{R}^{2}=0,99 ; \mathrm{F}(1,14)=1384,67$ & & \\
\hline Equação: PSC $=0,4777+0,0093$ x ANO & & \\
\hline
\end{tabular}

Fonte: Resultados da Pesquisa.

Legenda: $* * *$ corresponde à significância estatística no nível de $1 \%$.

Em termos percentuais, a relação entre a participação da mulher no mercado de trabalho e o período de tempo trouxe um coeficiente 0,93 . Significa dizer que a cada ano, a participação da mulher tem aumentado quase um ponto percentual no segmento contábil. Porém, cabe analisar se o aumento de mulheres no mercado brasileiro acompanha a Teoria da Discriminação Salarial (TDS), por meio de análise dos montantes recebidos. 
Contextualizado essas duas mudanças estruturais, verifica-se, na sequência, a estrutura de remuneração do setor contábil, analisando o aspecto temporal, a influência da educação, do gênero, do tipo de função e da idade nessa variável.

\subsection{Análise Temporal da Remuneração do Setor}

Nesta subseção são apresentados resultados que evidenciam como a remuneração do setor evoluiu ao longo do tempo compreendido pela amostra.A Figura 1 evidencia a relação entre remuneração média do setor, em salários mínimos, em relação ao período de tempo conforme se apresenta.

Figura 1 - Relação da remuneração média do setor com o tempo

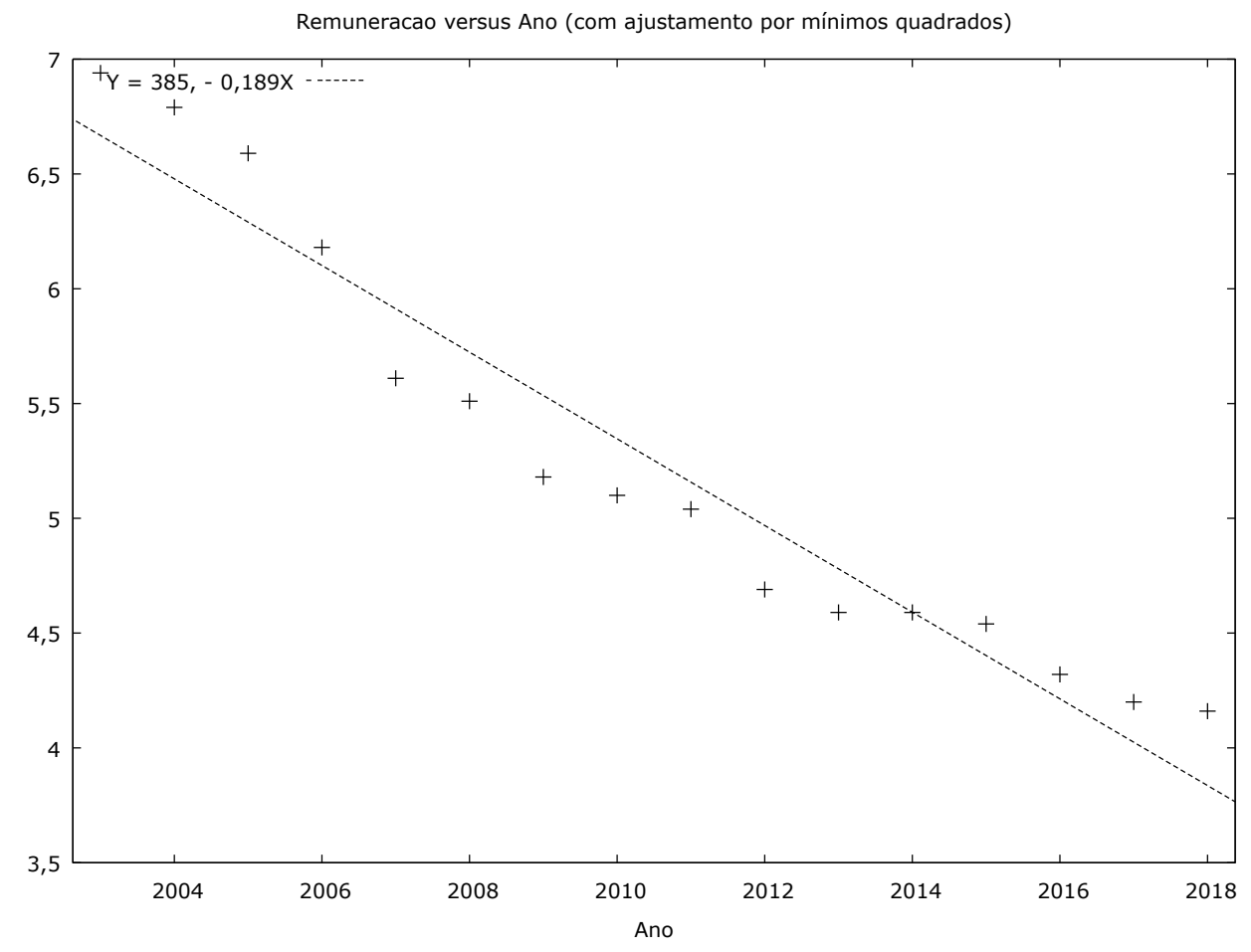

Fonte: Resultados da Pesquisa.

Observa-se que há uma tendência de queda da remuneração ao longo do tempo, revelada pela regressão linear simples entre remuneração média do setor (RMS) e o período de tempo (ANO). Esse resultado é evidenciado também na Tabela 6.

Tabela 6 - Evolução da remuneração média

\begin{tabular}{lcc}
\hline & Coeficiente & Significância \\
\hline Constante & 68,565 & $* * *$ \\
$\mathrm{ANO}$ & $-0,1888$ & $* * *$ \\
\hline $\mathrm{R}^{2}=0,93 ; \mathrm{F}(1,14)=191,80$ & & \\
\hline Equação: $\mathrm{PSC}=68,565-0,1888$ x ANO & & \\
\hline
\end{tabular}

Fonte: Resultados da Pesquisa.

Legenda: *** corresponde à significância estatística no nível de $1 \%$.

O salário médio da amostra, mensurado em salários mínimos, sofreu no período analisado, uma reduão de $18,8 \%$. Com efeito, em 2003 a remuneração média do trabalhador no setor contábil era de 7,15 salários; em 2018, caiu para 4,16 salários. É importante destacar, no entanto, que isso foi 
uma característica da economia do período, conforme dados obtidos na pesquisa, mas não evidenciados aqui.

Com efeito, usando os dados totais de todos os trabalhadores constantes da base de dados, a expressão também apresenta um coeficiente angular negativo, indício de redução do salário médio. Isso pode ser decorrente de uma mudança no valor do salário mínimo do período ou de uma alteração estrutural na remuneração do trabalho na economia brasileira ou ambos.

De qualquer forma, para certificar a existência de perda salarial no período, procedeu-se uma análise da diferença entre a remuneração do setor contábil e a remuneração da economia. Calculouse, então, uma regressão linear entre essa diferença - variável dependente - e o ano - variável independente - para verificar se está ocorrendo uma perda salarial comparativa no setor. A Figura 2 apresenta os resultados dessa diferença ao longo do tempo. Por outro lado,a regressão linear da Diferença da Remuneração Média (DRM) no tempo é apresentada na Tabela 7.

Figura 2 - Diferença da remuneração média do setor ao longo do tempo

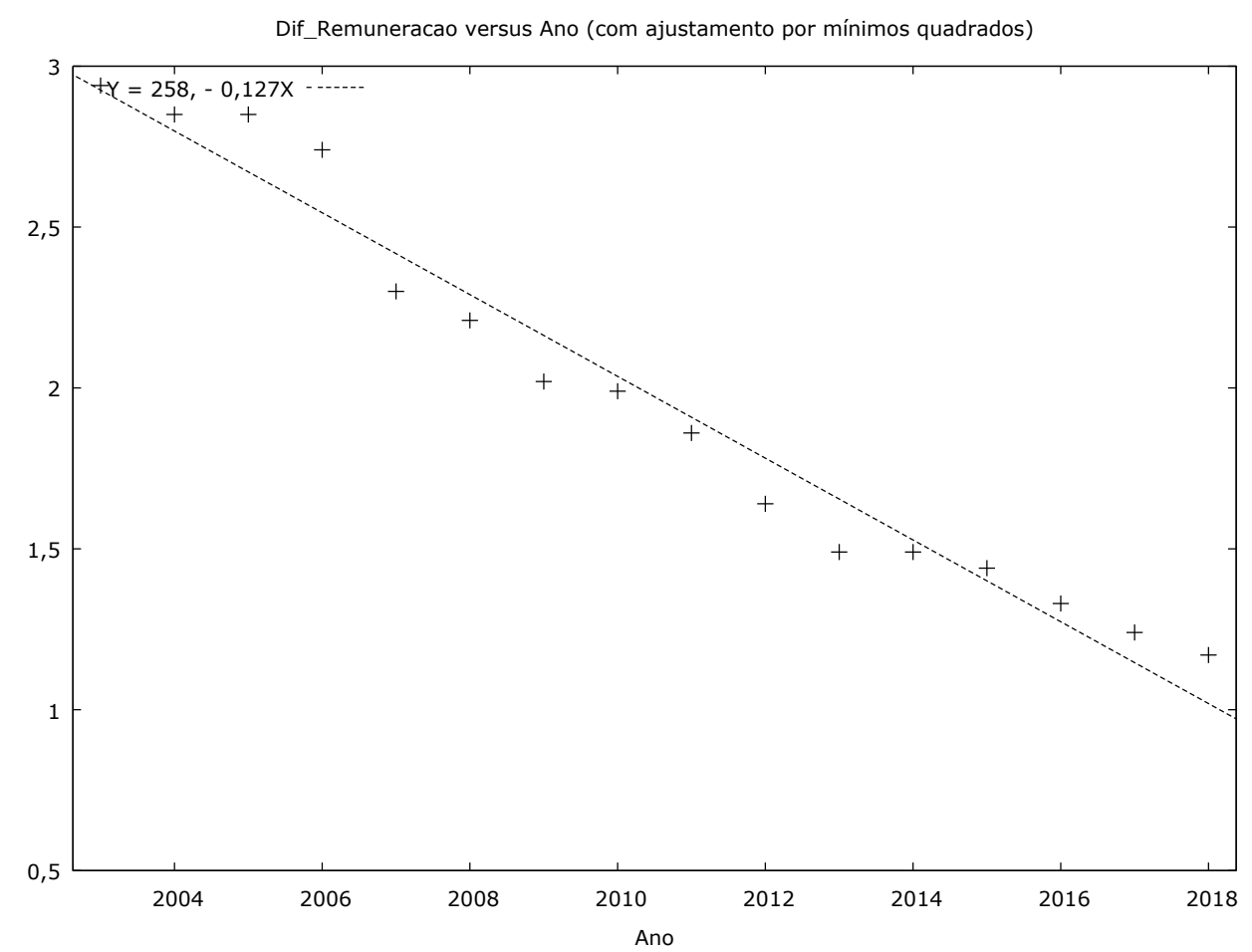

Fonte: Resultados da Pesquisa.

Os dados apresentados na Figura 2 evienciam que, ao longo dos últimos anos, a diferença salarial do setor contábil para todos os trabalhadores constantes da base de dadostem diminuído substancialmente, demonstrando que o salário do profissional contábil tem se aproximado cada vez mais da média salarial da economia.

Tabela 7 - Diferença na Remuneração Média (Setor Contábil x Economia)

\begin{tabular}{lcc}
\hline & Coeficiente & Significância \\
\hline Constante & 3,053 & $* * *$ \\
ANO & $-0,1271$ & $* * *$ \\
\hline $\mathrm{R}^{2}=0,96 ; \mathrm{F}(1,14)=378,76$ & & \\
\hline Equação: PSC $=3,053-0,1271$ x ANO & & \\
\hline
\end{tabular}

Legenda: $* * *$ corresponde à significância estatística no nível de $1 \%$.

Fonte: Resultados da Pesquisa. 
A Tabela 7, por sua vez, evidencia o resultado inferencial dessa diferença na remuneração média.

Esse resultado apurado evidencia que a diferença salarial entre os trabalhadores do setor contábil caiu com o passar do tempo. Assim, o atrativo salarial para a escolha da profissão é cada vez menor. Apesar disso, um teste de diferença de médias para a última informação disponibilizada revelou que a média de remuneração ainda é relevante; que a remuneração do profissional contábil ainda é atrativa se comparada com a média da remuneração da economia, sendo relevante ainda a escolha da profissão contábil para se atuar. Porém, se essa diferença continuar reduzindo, a profissão pode se tornar pouco atrativa no longo prazo.

\subsection{Análise Temporal da Influência da Educação}

O fato de o trabalhador assalariado investir na sua escolaridade pode ou não ser recompensado pelo mercado por meio de uma maior remuneração. Em razão das características do trabalho na área contábil, provavelmente o principal ponto de inflexão esteja na decisão de fazer o curso superior ou permanecer com o curso técnico.

A base de dados usada para este estudo não permite verificar, precisamente, essa diferença por dois motivos: (a) durante o período de análise alguns trabalhadores estavam cursando o ensino superior, mas não é possível identificar cada um deles; (b) a base não diferencia o tipo de curso realizado por cada trabalhador. Nesse último caso, é possível que um trabalhador do setor contábil tenha como formação uma área correlata, por exemplo, e isso não foi captado pelos dados disponíveis, para cargo diferente de contador.

Diante dessas dificuldades, a análise realizada aqui é muito mais entre só ter o ensino médio ou fazer um curso superior, independente se relacionado diretamente com a área ou não. Os autores desta pesquisa consideram que esse fato, por si só, já é um ponto importante, pois denota que o profissional está em busca de um grau de escolaridade acima dos demais, que busca alcançar o nível superior, independente da área do curso. Assim, da amostra dos trabalhadores do setor contábil, selecionou-se somente aqueles que concluíram o ensino médio completo vis-à-vis àqueles que fizeram o curso superior. Conforme dados apresentados anteriormente na Tabela 1, esses dois grupos representam $80 \%$ do total, o que poderia garantir a representatividade dos testes apresentados a seguir.

O ponto relevante é verificar se ter o curso superior garantiria um bônus salarial. Uma forma é verificar se a média do salário de quem possui o ensino médio completo é substancialmente inferior ao salário de quem possui o ensino superior. No primeiro caso, a média era de 2,41 Salários Mínimos $(\mathrm{SM})$ no final de $2016(\mathrm{n}=143.909 ; \mathrm{DP}=1,78)$ versus 5,71 SM para que tinha o curso superior $(\mathrm{n}=$ 240.303, $\mathrm{DP}=6,02)$. O teste de média revela um $\mathrm{t}=251,019$, confirmando que as médias são diferentes. Portanto, em conformidade com a Teoria do Capital Humano, quanto maior for a qualificação do profissional, maior tende a ser o seu rendimento (Blaug, 1976; Schultz, 1961; Leiby, \& Madsen, 2017).

Apesar de ser interessante financeiramente ter o ensino superior, em comparação com o trabalhador que possui o ensino médio completo, essa diferença está reduzindo a cada ano. Assim, a relação entre essa diferença de remuneração e o período de tempo é evidenciada na Tabela 8:

Tabela 8 - Modelo de Regressão Linear Simples para a Variável Dependente DR

\begin{tabular}{lcc}
\hline & Coeficiente & Significância \\
\hline Constante & 8,203 & $* * *$ \\
$\mathrm{ANO}$ & $-3,159$ & $* * *$ \\
\hline $\mathrm{R}^{2}=0,98 ; \mathrm{F}(1,14)=662,77$ & & \\
\hline Equação: $\mathrm{PSC}=8,203-3,159$ x ANO & & \\
\hline
\end{tabular}

Fonte: Resultados da Pesquisa.

Legenda: *** corresponde à significância estatística no nível de $1 \%$. 
O resultado obtido indica que a cada ano a diferença de remuneração entre o trabalhador do setor contábil com formação superior tem diminuído em relação àquele com formação do segundo grau. Esse resultado está de acordo com os estudos de Blaug (1976), que afirma que quanto maior o nível de educação do profissional, melhores serão os seus retornos futuros, e também, com os autores Martins e Monte (2010), os quais apontam que o nível superior gera um aumento salarial.

\subsection{Análise Descritiva da Influência do Gênero}

Alguns autores acreditam que a escolaridade pode ser uma forma de reduzir as diferenças salariais existentes na sociedade entre os gêneros (Esteve-Volart, 2004; Galete, 2010; Mattei, \& Baço, 2017; Santana Júnior, \& Callado, 2017). Assim, tentou-se verificar se o fato da mulher não ter o diploma ser um fator de redução da diferença salarial. Uma primeira forma de cálculo foi determinar a diferença salarial entre homem e mulher para aqueles que possuem ensino médio completo em comparação com aqueles que possuem ensino superior completo.

Para 2018 tem-se a proporção da remuneração média de homens e mulheres, respectivamente em salários mínimos (SM): 2,74 - 2,24 SM para o ensino médio; e 7,31 - 4,63 SM, para aqueles que possuem o ensino superior completo. O resultado, em SM, mostra que o ensino superior tende a aumentar a diferença dessa remuneração. Entretanto, talvez mais interessante seja determinar a diferença relativa, por meio da comparação entre a remuneração da mulher e a remuneração do homem.

Para aqueles que concluíram o ensino médio era de $81,75 \%$, versus um percentual de $63,34 \%$ para os que possuem o ensino superior completo, uma vez que o adicional de estudo tende a aumentar também a distância relativa de remuneração presente no nível menor de escolaridade. Além disso, analisando somente a remuneração média de mestres e doutores, para o ano de 2018, a disparidade salarial ainda persiste em nível elevados: a mulher, com mestrado, no setor contábil tinha rendimentos que correspondia a $64,17 \%$ daqueles recebidos pelo homem; com doutorado, o percentual era de $62,92 \%$.

Apesar de propiciar ganhos na remuneração, o ensino superior não tem contribuído com a redução da diferença salarial entre os gêneros. Um fato importante é que ao fazer o mestrado e o doutorado a disparidade na economia reduz, em $64,2 \%, 69,6 \%$ e 80,5\% para curso superior, mestrado e doutorado, respectivamente. Enquanto isto não está presente no setor contábil que apresentou índices de 63,3\%,64,2\% e 62,9\%, respectivamente, para curso superior, mestrado e doutorado.

Esses resultados indicam a existência de discriminação salarial entre os gêneros, pois conforme aponta a Teoria da Discriminação Salarial (TDS), mesmo com a mesma qualificação (ensino superior) as mulheres tendem a receber salários menores que os homens, corroborando assim com os estudos de Brighenti, Jacomossi e Silva (2015), Mihaila (2016), Santana Júnior e Callado (2016), Silva, Dal Magro e Silva (2016), Silva et al. (2018), Vandenbergh (2011) e Borsato Junior, Zabotti e Araújo (2020), os quais apontam a existência de discriminação de gênero nas remunerações recebidas pelas mulheres.

\subsection{Análise Descritiva do Tipo de Função}

A distribuição da formação pela ocupação de cada trabalhador para o final do ano de 2018 está evidenciada na Tabela 9. Quase 83\% dos contadores e auditores possuem curso superior completo, enquanto que este percentual é somente de $32 \%$ para os escriturários e quase $52 \%$ para aqueles que trabalham como técnico.

Esse resultado já era esperado, já que a ocupação de contador e auditor é usualmente mais complexa que a de técnico e que, por sua vez, é mais complexa que de escriturário. Apesar da menor qualificação dos técnicos e escriturários, é importante notar que em uma análise temporal há um nítido avanço dessas duas ocupações. Em 2003, por exemplo, somente 14\% dos escriturários e 27\% dos técnicos possuíam curso superior, versus 32\% e 52\%, nesta ordem, em 2018. 
Tabela 9 - Distribuição da função do trabalhador pela formação

\begin{tabular}{lcccc}
\hline \multicolumn{1}{c}{ Escolaridade } & $\begin{array}{c}\text { Contadores e } \\
\text { Auditores }\end{array}$ & Técnicos & Escriturários & Total \\
\hline Ensino Médio Incompleto & 1.191 & 1.206 & 12.740 & 15.137 \\
Ensino Médio Completo & 13,734 & 11.649 & 118.526 & 143.909 \\
Ensino Superior Incompleto & 12,694 & 3.435 & 55.094 & 71.223 \\
Ensino Superior Completo & 137.635 & 17.607 & 89.519 & 244.761 \\
\hline Total & $\mathbf{1 6 5 , 2 5 4}$ & $\mathbf{3 3 . 8 9 7}$ & $\mathbf{2 7 5 . 8 7 9}$ & $\mathbf{4 7 5 . 0 3 0}$ \\
\hline
\end{tabular}

Fonte: Resultados da Pesquisa.

Além disto, em termos comparativos, reduziu-se a participação dos técnicos na relação dos trabalhadores do mercado de trabalho formal: era de 19\% em 2003 e caiu para 7\% em 2018. Em termos quantitativos isso traduz em uma redução de 7.141 vagas para essa ocupação. Ao mesmo tempo, aumentou o número de contadores e auditores e de escriturários: no período o aumento foi acima de $145 \%$. Parte desse comportamento pode ser explicada pela Lei n. 12.249/10, do curso técnico em contabilidade e pela expansão, concomitante, do curso superior no Brasil (Brasil, 2010).

\subsection{Análise Descritiva e Inferencial da Idade do Trabalhador}

No setor contábil ocorreu algo diferente da população de trabalhadores no Brasil: a redução da idade média dos trabalhadores da área. Considerando todos aqueles que estavam no mercado formal em todos os setores da economia, em 2003 a média de idade era de 35,17 anos; anos depois, em 2018, essa média tinha aumentado para 38,89 anos. Já no setor contábil também ocorreu um aumento, em proporção menor, na idade média dos trabalhadores: 35,38 anos para 35,84 anos de idade, no mesmo período. A estrutura que compara a idade média pela escolaridade encontra-se ilustrada na Tabela 10.

Tabela 10 - Idade média por formação

\begin{tabular}{cc}
\hline Escolaridade & Idade Média \\
\hline Ensino Médio Incompleto & 35,78 \\
Ensino Médio Completo & 35,96 \\
Ensino Superior Incompleto & 30,14 \\
Ensino Superior Completo & 37,44 \\
\hline Total & $\mathbf{3 5 , 8 4}$ \\
\hline
\end{tabular}

Fonte: Resultados da Pesquisa.

É possível perceber que nas classes de escolaridade constantes na Tabela 10 é evidenciado o fato de o trabalhador está em processo de formação, pois no grupo denominado superior incompleto a média de idade é menor.

Por meio desses resultados expostos, entende-se que a profissão contábil no Brasil vem passando por mudanças estruturais significativas, devido às mudanças na concentração geográfica, escolaridade, gênero, remuneração, tipo de função e idade do trabalhador compreendido como contador ou auditor, técnicos em contabilidade e escriturários em contabilidade. A análise efetuada ao longo deste trabalho também foi realizada para o cargo de auditor; porém, os resultados obtidos não diferenciaram, no tempo, daqueles obtidos para o setor contábil como um todo.

\section{CONSIDERAÇÕES FINAIS}

Ao comparar a remuneração dos profissionais contábeis com o salário mínimo de todos os trabalhadores, verificamos que a remuneração média desses trabalhadores apresenta uma queda em torno de $20 \%$ ao ano; a diferença salarial, entre o setor contábil e a média total da economia, caiu 
com o passar do tempo, o que poderia indicar menor atração do mercado de trabalho contábil. A partir dessa mudança estrutural, este estudo focou outros aspectos mais específicos dos profissionais do setor contábil. Nessa direção, os resultados da pesquisa evidenciam a mudança no perfil dos trabalhadores no setor contábil de 2003 a 2018. Em se tratando de educação, verificou-se que, a cada ano, mais profissionais com nível superior estão se inserindo no mercado de trabalho contábil. Outro resultado referente ao nível de educação dos profissionais contábeis demonstrou que anos adicionais de estudo tende a aumentar o nível de remuneração dos profissionais no mercado: os trabalhadores que apresentam maior nível de educação tendem a ter salários maiores e a diferença salarial entre nível médio e superior vem aumentando nos anos analisados. Também é importante destacar o aumento na inclusão no mercado de trabalho de profissionais com titulação stricto sensu.

Quanto ao gênero e a diferença salarial entre homens e mulheres na profissão contábil, há um crescimento no número de trabalhadores do gênero feminino, um crescimento anual de quase um ponto percentual da participação dessas trabalhadoras no mercado de trabalho no período estudado. Apesar desse crescimento observado, os resultados apontam que tanto com nível médio, quanto com nível superior, os profissionais de gênero masculino recebem maiores salários do que profissionais de gênero feminino. Ao completar o ensino superior, a diferença salarial entre homens e mulheres vem aumentando nos últimos anos. Mesmo propiciando ganhos no salário, o ensino superior não contribui com a redução da diferença salarial entre os gêneros. Esse resultado está de acordo com Galete (2010), que comenta que o diferencial do salário entre os gêneros "[...] pode ser interpretado como resultado do tratamento discriminatório pelos empregadores". O estudo de Borsatto Junior, Zabotti e Araújo (2020) evidenciou que a discriminação salarial por sexo biológico reduz em média $28 \%$ da remuneração de contadoras mulheres.

Os resultados sobre o tipo de ocupação dos profissionais da contabilidade apontam para um maior número de escriturários contábeis do que contadores, auditores e técnicos em contabilidade. Esta é uma análise estática. Entretanto, em termos de evolução, percebe-se que há um aumento de participação dos contadores, auditores e escriturários no mercado de trabalho pode ser explicado pela expansão dos cursos de bacharelado em Ciências Contábeis no Brasil. Esse achado é suportado por Ramirez (2011) ao apontar que o curso nasceu mediante uma necessidade do mercado de trabalho; a expansão de instituições de ensino que o ofertam gerou, como esperado, um aumento de profissionais inseridos nesse mercado de trabalho.

Por fim, quanto à idade dos trabalhadores contábeis brasileiros, há uma redução da idade média desses profissionais ao longo dos anos analisados. Enquanto todos os setores da economia evidenciam um aumento na idade média dos profissionais, o setor contábil apresenta uma redução no mesmo período. Outro fato que chama atenção é que no grupo dos profissionais que cursam o ensino superior, a idade média é mais reduzida entre os profissionais que possuem ensino médio incompleto, médio completo e superior completo.

O presente estudo possui implicações teóricas, práticas e sociais. Do ponto de vista teórico, este trabalho avança por analisar especificamente o mercado de trabalho contábil e por fornecer resultados que vão além da escolaridade e gênero. Os estudos de Araújo e Antigo (2015), Brighenti, Jacomossi e Silva (2015), Galete (2010), Gomes e Souza (2018), Martins et al. (2009), Martins e Monte (2010), Santana Júnior e Callado (2017), Silva, Dal Magro e Silva (2016), Silva et al. (2018), fornecem evidências de que a remuneração percebida por profissionais no mercado de trabalho brasileiro - geral e contábil - é substancialmente afetada por aspectos relacionados à qualificação e ao gênero desses trabalhadores.

Este estudo avança por utilizar um recorte temporal maior de análise (2003 a 2018) e por, além de corroborar os estudos anteriores relacionados à escolaridade e gênero, discutir aspectos sobre concentração geográfica, remuneração ao longo do tempo, tipo de função e idade do trabalhador, fornecendo assim novos insights para a literatura.

Do ponto de vista prático, este estudo fornece contribuições significativas ao segmento contábil, ao discutir pontos que alertam o empregador, empregado, conselhos profissionais e 
sindicatos sobre a ocorrência de problemas estruturais na profissão, como a diferença salarial entre os gêneros, mediante os maiores montantes de salários oferecidos aos profissionais do gênero masculino em detrimento do gênero feminino.

Esses pontos merecem atenção ao fornecer evidências sobre o perfil do trabalhador e problemas relacionados à discriminação no setor contábil. Por fim, sob o ponto de vista social, este estudo visa contribuir com a sociedade por evidenciar que mesmo em um segmento de trabalho com uma ampla disponibilidade de cargos com salários atrativos, há problemas estruturais, como a redução salarial ao longo do tempo e a discriminação salarial de gênero. Os achados deste estudo fornecem evidencias que podem contribuir para a escolha de determinado indivíduo ao optar por um curso superior em Ciências Contábeis, mediante um quadro amplo sobre o mercado de trabalho dessa profissão.

Importante ressaltar que os resultados deste estudo são válidos para inferências do mercado de trabalho assalariado contábil antes do período de pandemia da Covid-19, em 2020, que afetou de forma substancial as relações de trabalho no mercado brasileiro. Esta poderia ser uma sugestão de pesquisa futura. Entretanto, no início de 2020, o governo federal alterou a base de dados, podendo ser mais um motivo para dificultar uma comparação temporal após o período utilizado neste estudo.

Algumas limitações puderam ser observadas, o que não diminuiu a importância desta pesquisa: a possível má classificação dos empregados por parte dos empregadores em famílias, conforme $\mathrm{CBO}$, que não deveriam ser registrados, podendo distorcer alguns dos números apresentados; a utilização apenas de dados do mercado de trabalho formal, por falta de acesso das informações de trabalhadores informais.

Sugerimos que pesquisas futuras façam uma análise com dados individualizados, bem como uma análise do mercado informal da profissão contábil. Sugerimos também pesquisas que analisem as mudanças estruturais na profissão contábil em períodos após a adoção das IFRS e após a implementação de obrigações acessórias eletrônicas que tornaram bem mais complexas as informações contábeis.

\section{REFERÊNCIAS}

Alves, F. E. (2015). Análise da renda dos profissionais de contabilidade no Estado de Pernambuco: contador x técnico em contabilidade. Dissertação de Mestrado em Economia, Universidade Federal do Ceará.

Andrade, P. H. P., Gonçalves, E., \& Freguglia, R. S. (2014). Concentração geográfica de ocupações por regiões metropolitanas brasileiras. Revista Brasileira de Estudos Regionais e Urbanos, 8(2), 155-173.

Araújo, J. P. F. D., \& Antigo, M. F. (2016). Desemprego e qualificação da mão de obra no Brasil. Revista de Economia Contemporânea, 20(2), 308-335.

Barron, J. M., Black, D. A., \& Loewenstein, M. A. (1993). Gender differences in training, capital, and wages. Journal of Human Resources, 28(2), 343-364.

Barros, R. P. D., Henriques, R., \& Mendonça, R. (2000). Desigualdade e pobreza no Brasil: retrato de uma estabilidade inaceitável. Revista Brasileira de Ciências Sociais, 15(42), 123-142.

Becker, G. (1964). Human Capital: A Theoretical and Empirical Analysis, with Special Reference to Education (1964). University of Illinois at Urbana-Champaign's Academy for Entrepreneurial Leadership. Historical Research Reference in Entrepreneurship. Disponível em: https://papers.ssrn.com/sol3/papers.cfm?abstract_id=1496221.

Blaug, M. (1976). The empirical status of human capital theory: A slightly jaundiced survey. Journal of Economic Literature, 14(3), 827-855.

Bureau of Labor Statistics. (2016). Occupational Outlook Handbook, Accountants and Auditors. U.S. Department of Labor.

Borsatto Junior, J. L., Zabotti, E. D., \& Araújo, M. P. (2020). Gênero, Etnia e Raça: Débito ou Crédito na Contabilidade?. Contabilidade Vista \& Revista, 31(2), 68-94. 
Decreto n. 76.900, de 23 de dezembro de 1975. (1975, 24 dezembro). Institui a Relação Anual de Informações Sociais - RAIS e dá outras providências. Diário Oficial da União.

Lei n. 12.249, de 11 de junho de 2010. (2010). Institui a realização do exame de suficiência para os profissionais Bacharéis em Ciências Contábeis. Diário Oficial da União.

Portaria Ministerial no 357 de 9 de outubro de 2002. (2002). Aprova a Classificação Brasileira de Ocupações - CBO/2002, para uso em todo território nacional e autoriza a sua publicação. Coordenação de Estudos Legislativos

Brighenti, J., Jacomossi, F., \& da Silva, M. Z. (2015). Desigualdades de gênero na atuação de contadores e auditores no mercado de trabalho catarinense. Enfoque: Reflexão Contábil, 34(2), 109-122.

Carneiro, P., Heckman, J. J., \& Masterov, D. V. (2005). Labor market discrimination and racial differences in premarket factors. The Journal of Law and Economics, 48(1), 1-39.

Cavalcante, G. M. M. R. (2010). A precarização do trabalho e das políticas sociais na sociedade capitalista: fundamentos da precarização do trabalho do assistente social. Libertas, 10(1), 1-24.

Dedecca, C. S. (2002). Reorganização econômica, absorção de mão de obra e qualificação. Brazilian Journal of Political Economy, 22(2), 253-272.

Esteve-Volart, B. (2004). Gender discrimination and growth: Theory and evidence from India. Working Paper Series.

Fávero, L. P. (2015). Manual de Análise de Dados. Elsevier.

Galete, R. (2010). Discriminação no mercado de trabalho formal: uma análise exploratória por género, a partir dos dados da Relação Anual de Informações Sociais-RAIS 2007. Administração, Contabilidade $e$ Economia, 9(1-2), 135-152.

Gomes, M. T. S. (2002). As mudanças no mercado de trabalho e o desemprego em Presidente Prudente/SPBrasil. Scripta Nova. Revista Electrónica de Geografía y Ciencias Sociales, 6(119), 32.

Gomes, M. R., \& Souza, S. D. C. I. D. (2018). Assimetrias salariais de gênero e a abordagem regional no brasil: uma análise segundo a admissão no emprego e setores de atividade. Revista de Economia Contemporânea, 22(3).

Ha, S., Nguyen, H., Nguyen, N., \& Do, D. (2020). The outside determinants influencing quality of accounting human resources for sustainability through the lens accounting service firms in Hanoi, Vietnam. Management Science Letters, 10(3), 543-550.

Kyriakidou, O., Kyriacou, O., Özbilgin, M., \& Dedoulis, E. (2016). Equality, diversity and inclusion in accounting. Critical Perspectives on Accounting, 35, 1-12.

Leiby, J., \& Madsen, P. E. (2017). Margin of safety: Life history strategies and the effects of socioeconomic status on self-selection into accounting. Accounting, Organizations and Society, 60, 21-36.

Lima, R. (1980). Mercado de trabalho: o capital humano e a teoria da segmentação. Pesquisa e Planejamento Econômico, 10(1), 217-272.

Martins, O. S., \& Monte, P. A. (2010). Fatores determinantes da variação salarial dos mestres em contabilidade. Pensar Contábil, 12(49), 13-22.

Martins, O. S., de Vasconcelos, A. F., Brasil, A. M. S., do Monte, P. A., \& Leite Filho, P. A. M. (2009). Fatores que influenciam os salários dos contadores à luz das teorias econômicas do emprego: um estudo exploratório na Paraíba e no Rio Grande do Norte. Revista Brasileira de Contabilidade, (176), 72-85.

Mattei, T. F., \& Baço, F. M. B. (2017). Análise das desigualdades salariais entre homens e mulheres no mercado de trabalho de Santa Catarina. DRd-Desenvolvimento Regional em debate, 7(2), 96-117.

Mihăilă, R. (2016). Female labor force participation and gender wage discrimination. Journal of Research in Gender Studies, 6(1), 262-268. 
Mincer, J. (1958). Investment in human capital and personal income distribution. Journal of Political Economy, 66(4), 281-302.

Pires, C. B., Ott, E., \& Damacena, C. (2010). A formação do contador e a demanda do mercado de trabalho na região metropolitana de Porto Alegre (RS). Revista Base (Administração e Contabilidade) da UNISINOS, 7(4), 315-327.

Ramirez, N. O. (2011). Política de Educação Superior no Brasil: A Expansão dos Cursos de Ciências Contábeis (1996 a 2009). Dissertação de Mestrado em Educação, Universidade Católica Dom Bosco, Campo Grande.

Santana Junior, G. M., \& Callado, A. L. C. (2017). Discriminação salarial entre homens e mulheres no mercado de trabalho dos contadores do nordeste brasileiro. Revista Mineira de Contabilidade, 18(2), 70-82.

Schultz, T. W. (1961). Investment in human capital. The American economic review, 51(1), 1-17.

Silva, J. C., Dal Magro, C. B., \& da Silva, M. Z. (2016). Gender inequality in accounting profession from the perspective of the glass ceiling. RACE-Revista de Administração, Contabilidade e Economia, 15(2), 447-474.

Silva, J. C., Dal Magro, C. B., Gorla, M. C., \& da Silva, M. Z. (2018). Glass ceiling in the accounting profession: Evidence in Brazilian companies. Contaduría y administración, 63(2), 1-23.

Souza, M. C. C. D. (1978). Mercado de trabalho: abordagens duais. Revista de administração de empresas, 18(1), 59-69.

Vandenberghe, V. (2011). Firm-level Evidence on Gender Wage Discrimination in the Belgian Private Economy. Labour, 25(3), 330-349.

Williamson, R. (2019). Wage Disparity in the Accounting Profession and Information Quality. Ph.D. Dissertation in Accounting, College of Business and Economics at the University of Kentucky.

Zhou, Y., \& Yin, W. (2020). New Improvement of Labor Accounting in the Sharing Economy. Advances in Mathematical Physics, 1-8. 